\title{
Differential Effects of Amygdala, Orbital Prefrontal Cortex, and Prelimbic Cortex Lesions on Goal-Directed Behavior in Rhesus Macaques
}

\author{
Sarah E. V. Rhodes and Elisabeth A. Murray \\ Section on the Neurobiology of Learning and Memory, Laboratory of Neuropsychology, National Institute of Mental Health, National Institutes of Health, \\ Bethesda, Maryland 20892
}

\begin{abstract}
We assessed the involvement of the orbital prefrontal cortex (PFo), the prelimbic region of the medial prefrontal cortex (PL), and the amygdala in goal-directed behavior. Rhesus monkeys were trained on a task in which two different instrumental responses were linked to two different outcomes. One response, called "tap," required the monkeys to repeatedly touch a colored square on a video monitor to produce one kind of food reward. The other response, called "hold," required persistent contact of an identical stimulus, and it produced a different kind of food reward. After training, we assessed the effects of sensory-specific reinforcer devaluation as a way to probe each monkey's use of goal-directed behavior. In this procedure, monkeys were allowed to consume one of the two foods to satiety and were then tested for tap/hold preference under extinction. Unoperated control monkeys showed a reduction in the response associated with obtaining the devalued food, called the "devaluation effect," a hallmark of goal-directed behavior. Monkeys with bilateral lesions of PFo or the amygdala exhibited significantly reduced devaluation effects. Results from monkeys with PL lesions were equivocal. We conclude that both PFo and the amygdala play a significant role in goal-directed behavior in monkeys. Notably, the findings for PFo challenge the idea that orbital and medial prefrontal regions are exclusively dedicated to object- and action-based processes, respectively.
\end{abstract}

\section{Introduction}

Goal-directed behavior is a vital component of our behavioral repertoire, enabling us to "control our environment in the service of our desires and needs" (Dickinson and Balleine, 1994). It is thought to depend on knowledge about the causal relationship between actions and the goals to which they lead, including knowledge about the incentive value of the goal (Adams and Dickinson, 1981; Dickinson and Balleine, 1994), and is supported by associations between representations of an instrumental action (response) and its goal (outcome). To study the neural substrates of goal-directed behavior in monkeys, we devised a new instrumental task that allowed us to assess the influence on behavior of the value of the goal. If an action is goal directed, then reducing the value of the outcome should lead to a reduction in

\footnotetext{
Received Sept. 13, 2012; revised Nov. 29, 2012; accepted Dec. 19, 2012.

Author contributions: S.E.V.R. and E.A.M. designed research; S.E.V.R. and E.A.M. performed research; S.E.V.R. analyzed data; S.E.V.R. and E.A.M. wrote the paper.

This research was supported by the Intramural Research Program of the National Institute of Mental Health. We thank Steven Wise and Janine Simmons for their comments on a previous version of this manuscript. We are grateful to Yogita Chudasama, Emily Howland, Alicia Izquierdo, Peter Kaskan, Anna Prescott, Rachel Reoli, and Richard Saunders for help during surgery. We also thank Renee Hill and the staff of the Nuclear Magnetic Resonance Imaging Facility of the National Institute of Neurological Disorders and Stroke for assistance obtaining MR scans. Finally, we thank Ping-Yu Chen for help preparing figures and Yogita Chudasama, Alicia Izquierdo, Peter Rudebeck, and Katherine Wright for help with brain lesion reconstructions.

The authors declare no competing financial interests.

Correspondence should be addressed to Dr. Sarah E. V. Rhodes, Laboratory of Neuropsychology, National Institutes of Health/National Institute of Mental Health, Building 49, Room 1B/80, 49 Convent Drive, Bethesda, MD 20892-4415. E-mail: sarah.rhodes@mail.nih.gov.

DOI:10.1523/JNEUROSCI.4374-12.2013

Copyright $\odot 2013$ the authors $\quad 0270-6474 / 13 / 333380-10 \$ 15.00 / 0$
}

the action that produced the goal, a phenomenon called the "devaluation effect."

The present study had three principal aims: (1) to validate this novel task as a test of goal-directed behavior in monkeys; (2) to see whether prelimbic cortex (PL), a part of the medial prefrontal cortex (PFm), is critical for goal-directed behavior in monkeys, as it is in rats (Balleine and Dickinson, 1998; Corbit and Balleine, 2003; Killcross and Coutureau, 2003; Ostlund and Balleine, 2005); and (3) to explore the idea that the orbital prefrontal cortex (PFo) and the PFm are specialized for stimulus-outcome and response-outcome associations, respectively (Rudebeck et al., 2008; Camille et al., 2011; Rushworth et al., 2011).

To achieve the latter two aims, we tested the effects of PFo and PL lesions on performance of the new task, described below. To achieve the first aim, we examined the role of the amygdala, which is interconnected with these regions (Carmichael and Price, 1995; Ongür and Price, 2000), and is essential for goaldirected behavior (Balleine et al., 2003; Blundell et al., 2003; Corbit and Balleine, 2005; Ostlund and Balleine, 2008; Johnson et al., 2009).

Although several studies have examined the role of the frontal cortex in instrumental behavior in monkeys, they have generally involved reversal learning or matching tasks (Hadland et al., 2003; Kennerley et al., 2006; Rudebeck et al., 2008; Chudasama et al., 2012). With one exception (Chudasama et al., 2012), no studies have applied a direct test of whether the behavior is goal directed, defined as being an instrumental response influenced by the current value of the goal. In the present task, we trained monkeys to perform two different responses for two different 
food outcomes. One food was then devalued by selective satiation, and the influence of that reduction in value on each monkey's preference between the two instrumental responses was assessed. If an action is under the influence of the incentive value of the outcome, a devaluation effect will be seen.

Disruption of goal-directed behavior is implicated in a variety of behavioral disorders, including obsessive-compulsive disorder, depression, and addiction (Everitt and Robbins, 2005; Levy and Dubois, 2006; Gillan et al., 2011). Accordingly, elucidation of the neural substrates of goal-directed behavior may provide insight into these and other disorders.

\section{Materials and Methods Subjects}

A total of 18 male rhesus monkeys (Macaca mulatta), weighing between 6.3 and $13.9 \mathrm{~kg}$ at the beginning of the experiment, were used. The monkeys were experimentally sophisticated, having undergone a variety of cognitive tests before the present study. Three monkeys with bilateral excitotoxic amygdala lesions (group AMG) and four concurrently run unoperated controls (AMG-CON) served as subjects in previous studies of reward-based decision making and emotion (Izquierdo and Murray, 2005, 2007; Izquierdo et al., 2005). The case numbers correspond to those used by Izquierdo and Murray (2007). The two other monkeys used in that study were unavailable for testing. In addition, four monkeys with aspiration lesions of the prelimbic cortex (group PL), three with excitotoxic lesions of the orbital prefrontal cortex (group PFo), and four unoperated controls (group PL/PFo-CON) with training histories highly similar to the aforementioned groups and to each other were also tested.

All monkeys were housed individually in a temperature- and humidity-controlled room on a $12 \mathrm{~h}$ light/dark cycle (lights on at 7:00 A.M.), and testing occurred during the light period. During the study, the monkeys were given controlled access to primate chow supplemented with fruit to ensure sufficient motivation to respond in the test apparatus.

\section{Surgery}

During surgery, aseptic procedures were used. Anesthesia was induced with ketamine hydrochloride $(10 \mathrm{mg} / \mathrm{kg}$, i.m. ) and maintained with isoflurane (1.0-3.0\%, to effect). Heart rate, respiration rate, blood pressure, expired $\mathrm{CO}_{2}$, and body temperature were monitored during surgery, and isotonic fluids were given throughout. When the aspiration removals or injections were complete, the surgical site was closed in anatomical layers with sutures. The preoperative and postoperative treatment regimen consisted of dexamethasone sodium phosphate $(0.4 \mathrm{mg} / \mathrm{kg}$, i.m.) and Cefazolin antibiotic $(15 \mathrm{mg} / \mathrm{kg}$, i.m.) for $1 \mathrm{~d}$ before surgery and 1 week after surgery, to reduce swelling and prevent infection, respectively. At the end of surgery and for 2 additional days, the monkeys received the analgesic ketoprofen (10-15 mg, i.m.), followed by ibuprofen (100 mg) for the following $5 \mathrm{~d}$. Operations for two-stage surgeries were separated by a minimum of 2 weeks.

\section{Bilateral amygdala lesions}

All three monkeys received surgery in two stages to produce bilateral excitotoxic lesions of the entire amygdala. During the first surgery, injections of excitotoxins were made in the left hemisphere in one monkey (AMG 1) and in the right in the remaining two monkeys (AMG 2, AMG 4). During the second-stage surgery, monkeys received injections in the other hemisphere. After induction of anesthesia, monkeys were placed in a stereotaxic frame for the duration of the surgery, and a large bone flap was turned over the appropriate portion of the cranium. The injection sites were calculated based on landmarks that were visible on magnetic resonance imaging (MRI) scans obtained before the surgery. The sagittal sinus served as a landmark for the mediolateral coordinates, and the interaural plane (ear bars) served as a landmark for the anteroposterior and dorsoventral coordinates. The monkeys received between 15 and 22 injections to sites located $\sim 2 \mathrm{~mm}$ apart in each plane. Each injection consisted of $0.6-1.0 \mu \mathrm{l}$ of ibotenic acid $(10-15 \mu \mathrm{g} / \mu \mathrm{l} ; 0.2 \mu \mathrm{l} / \mathrm{min}$; Biosearch Technologies) administered via a 30 gauge Hamilton syringe held in a David Kopf Instruments manipulator. Before lowering the needle, small slits were made in the dura to allow the needle to pass unobstructed into the brain. The needle remained in place $2-3 \mathrm{~min}$ after each injection to limit diffusion of the toxin up the needle track. The intended lesion (see Fig. 1) encompassed the entire amygdala, including both basolateral and centromedial nuclear groups. On closing the surgical wound, $30 \mathrm{ml}$ of mannitol (25\%, $1 \mathrm{ml} / \mathrm{min}$, i.v. ) was administered to control edema.

\section{Bilateral PL lesions}

For the four monkeys in the PL group, bilateral aspiration lesions of PL were performed in a single stage. After induction of anesthesia, monkeys were placed in a head holder for the duration of the surgery, and a large, bilaterally symmetrical bone flap was turned over the frontal cortex. The dura was reflected toward the midline. Sulcal landmarks on the medial surface of the hemisphere were identified with the aid of an operating microscope, and the boundaries of the lesion were marked with a line of electrocautery. Then, using a combination of suction and electrocautery, the prelimbic cortex was removed by subpial aspiration through a finegauge metal sucker that was insulated, except at the tip. When the lesion in the first hemisphere was completed, the procedure was repeated in the other hemisphere. The intended lesion (see Fig. 2) corresponded approximately to area 32 of Carmichael and Price (1994). The lesion was approximately rectangular in shape and extended rostrocaudally along the full length of the rostral sulcus. The dorsal boundary of the lesion was $\sim 2$ $\mathrm{mm}$ ventral to the cingulate sulcus (at the midlevel of the genu of the corpus callosum), and the ventral boundary of the lesion was the fundus of the rostral sulcus. During surgery, monkeys were given $30 \mathrm{ml}$ of mannitol $(25 \%, 1 \mathrm{ml} / \mathrm{min}$, i.v.) to increase access to the medial surface of the hemispheres and to control edema.

\section{Bilateral PFo lesions}

All three monkeys that made up the PFo group received surgery in two stages to produce bilateral excitotoxic lesions of the PFo. During the first surgery, excitotoxin injections were made in the right hemisphere in two monkeys (PFo 1 and PFo 2) and in the left hemisphere in the remaining monkey (PFo 3). During the second-stage surgery, monkeys received injections in the other hemisphere. After induction of anesthesia, monkeys were put in a head holder for the duration of the surgery, and a large, bilaterally symmetrical bone flap was turned over the frontal cortex. The dura was opened with a crescent-shaped cut and then reflected toward the orbit. As with the PL lesions, sulcal landmarks on the orbital surface were identified with the aid of an operating microscope. Injections of excitotoxins were made into sites located $\sim 2 \mathrm{~mm}$ apart. Each injection consisted of $1.0 \mu \mathrm{l}$ of ibotenic acid $(10-15 \mu \mathrm{g} / \mu \mathrm{l}$; Sigma or Tocris Bioscience) injected via a hand-held Hamilton syringe with a 30 gauge needle. The monkeys received a mean of 80 injections per hemisphere (range, 71-119). The intended lesion (see Fig. 3) encompassed the entire $\mathrm{PFo}$, corresponding approximately to areas 11,13 , and 14 of Walker (1940); it extended from the fundus of the lateral orbital sulcus, laterally to the rostral sulcus on the medial surface of the hemisphere. The rostral boundary of the injections was a line joining the rostral tips of the medial and lateral orbital sulci. The caudal boundary of the injections was a line joining the most caudal points of the medial and lateral orbital sulci. During surgery, monkeys were given $30 \mathrm{ml}$ of mannitol $(25 \%, 1 \mathrm{ml} / \mathrm{min}$, i.v.) to increase access to the orbital surface and to control edema.

\section{Assessment of lesions}

The extent of the amygdala lesions was estimated by examination of T2-weighted MRI scans obtained within $12 \mathrm{~d}$ of surgery. For each of the three operated monkeys, MR images ( $1 \mathrm{~mm}$ slices) through the amygdala were matched to drawings of coronal sections of a representative rhesus monkey brain spaced at $1 \mathrm{~mm}$ intervals. Then, for each level, the region of hypersignal present in the scan was plotted onto the drawings (for more details on the lesion assessment method, see Izquierdo and Murray, 2004). Finally, the volume of the lesion was determined using a digitizing tablet (Wacom). Only one hemisphere could be evaluated in monkey AMG 2 because of a failure to obtain a postoperative MRI scan after surgery to the left hemisphere. Figure 1 shows MR images at the level of the amygdala in two of the monkeys that received excitotoxin injections. The volume of the amygdala lesion was expressed as a percentage of the 


\section{Intended lesion}
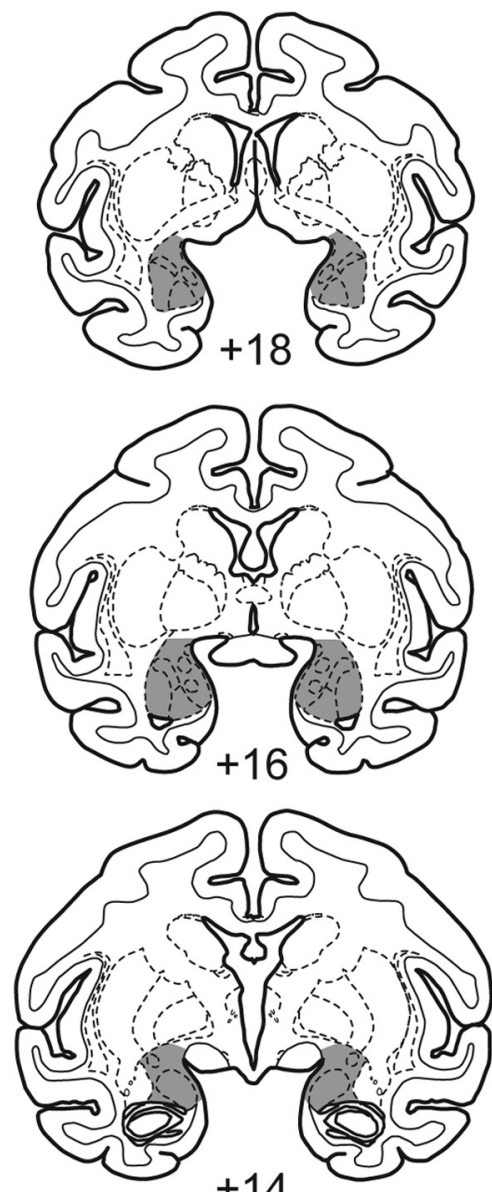

AMG 1
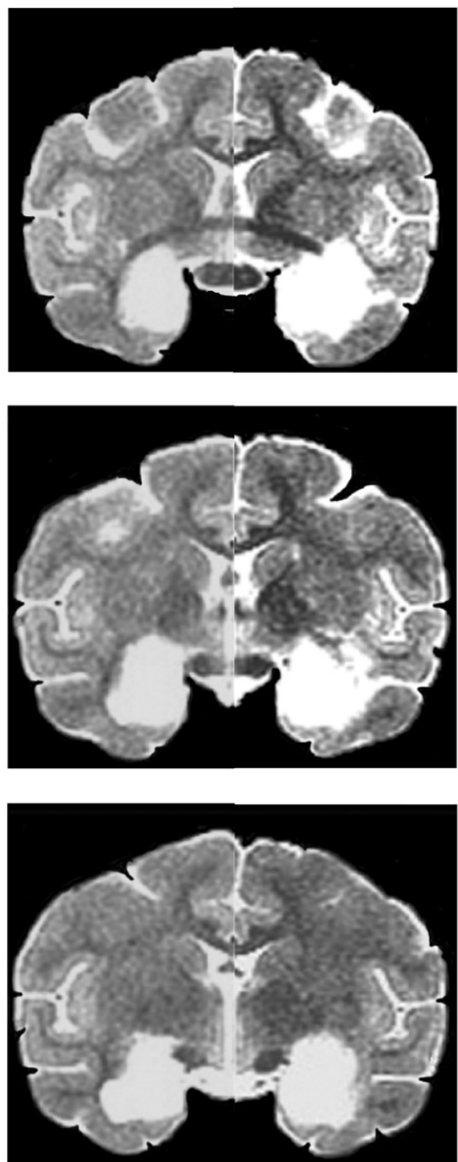

AMG 4
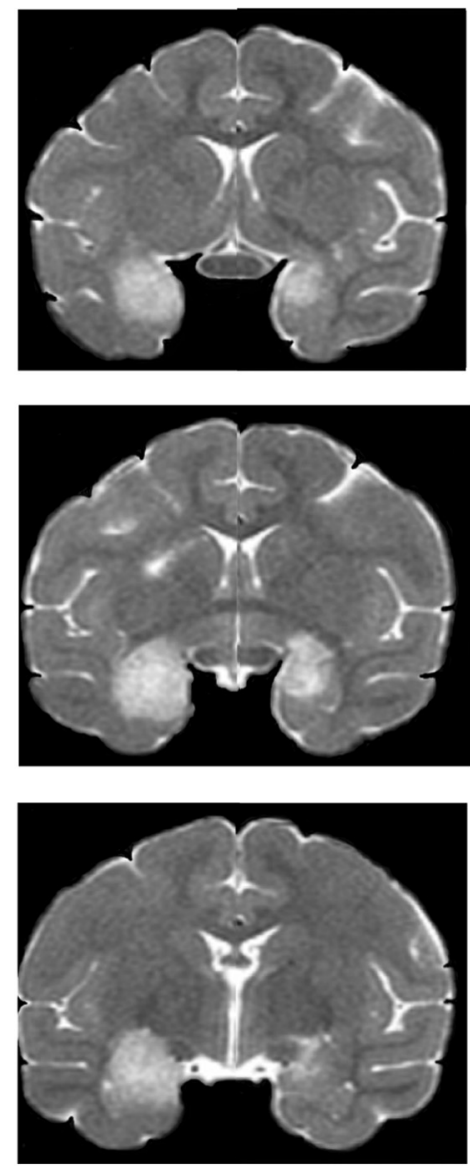

Figure 1. The left column shows drawings of coronal sections from a representative rhesus monkey brain depicting the location and extent of the intended bilateral amygdala lesion. The numerals indicate the distance (millimeters) of the sections from the interaural plane (0). The middle and right columns show the T2-weighted MR images from two monkeys that received injections of excitotoxins in the amygdala (AMG 1 and AMG 4) at levels matching the sections in the left column. For cases AMG 1 and AMG 4, the images of the left and right hemispheres are from two different MR scans; the two image halves have been joined at the midline for ease in viewing. The white areas are regions of hypersignal attributable to edema resulting from the injection of excitotoxin and are taken as a reflection of the extent of the amygdala lesion. Compare and contrast line drawings of the intended lesion (left column) with MR sections of the cases illustrated (middle and right columns).

overall volume of the amygdala in a representative monkey brain. We estimated that the lesions affected, on average, $94.6 \%$ of the volume of the amygdala (range, $85.2-100.0 \%$ ). Each of the monkeys sustained some inadvertent damage to adjacent structures. AMG 1 sustained slight bilateral damage to anterior portions of the entorhinal cortex and hippocampus and to portions of the ventral claustrum, substantia innominata, and piriform cortex. The other two monkeys sustained only very minor and unilateral damage to a subset of these regions.

The extent of the PL lesions was estimated by examination of T1weighted MRI scans obtained an average of 11 months after surgery. MR images ( $1 \mathrm{~mm}$ slices) through the lesion were matched to drawings of coronal sections of a representative rhesus monkey brain spaced at $1 \mathrm{~mm}$ intervals. For each of the four operated monkeys, the extent of tissue loss visible in the scan was plotted onto these sections. Figure 2 shows MR images at the level of the lesion in two cases in the PL group. Finally, the volume of the lesion was determined using a digitizing tablet (Wacom) and expressed as a percentage of the overall volume of the PL cortex in the representative brain.

The lesions were essentially as intended and averaged $65.4 \%$ of the volume of PL (range, 55.0-82.6\%). As for unintended damage, two monkeys (PL 3 and PL 4) sustained inadvertent damage to dorsomedial frontal cortex area 9 and the adjacent portion of anterior cingulate cortex unilaterally; in addition, one of these two monkeys (PL 4) sustained slight damage to the dorsomedial cortex in the opposite hemisphere. A third monkey (PL 2) sustained a small infarction involving the cortex on the dorsal convexity of the left hemisphere, at the anteroposterior level of the lesion, extending for a distance of $\sim 5 \mathrm{~mm}$.

The extent of the PFo lesions was estimated by examination of T2weighted MRI scans obtained within $7 \mathrm{~d}$ of surgery, using the same procedures as for the AMG lesions. Figure 3 shows MR images at the level of the lesion in two cases in the PFo group. The three monkeys sustained a mean of $70.7 \%$ damage to $\mathrm{PFo}$ (range, $64.3-80.1 \%$ ). The lesions were essentially as intended. There was some sparing in the deep layers of rostral PFo in all three monkeys. Inadvertent damage was limited to the ventral portion of the frontal polar cortex in two monkeys (PFo 1, PFo 3 ) and the caudal agranular orbital cortex in the third (PFo 2). In each case, the damage extended $\sim 2 \mathrm{~mm}$ and was restricted to one hemisphere.

\section{Apparatus}

Training took place in a sound- and light-attenuating chamber into which a monkey test cage was wheeled and securely fastened. The chamber was illuminated by a $15 \mathrm{~W}$ bulb, which allowed enough light for operation of a closed-circuit television camera. A fan mounted in the ceiling of the chamber provided ventilation and masked extraneous noise. Stimuli were presented on a 19-inch monitor with a touchsensitive screen that was positioned on the back wall of the chamber, 15 $\mathrm{cm}$ in front of the monkey cage. Two images $(5 \times 5 \mathrm{~cm})$ that differed in pattern and color were used as stimuli during both touch-screen training 


\section{Intended lesion}

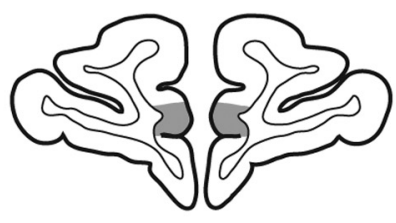

$+36$

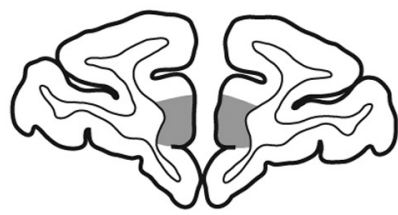

$+34$

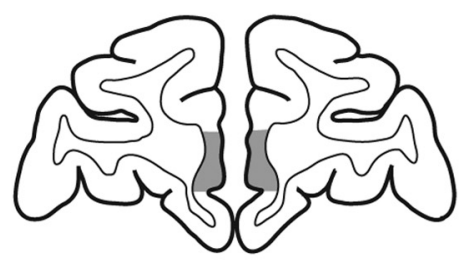

$+32$
PL 1
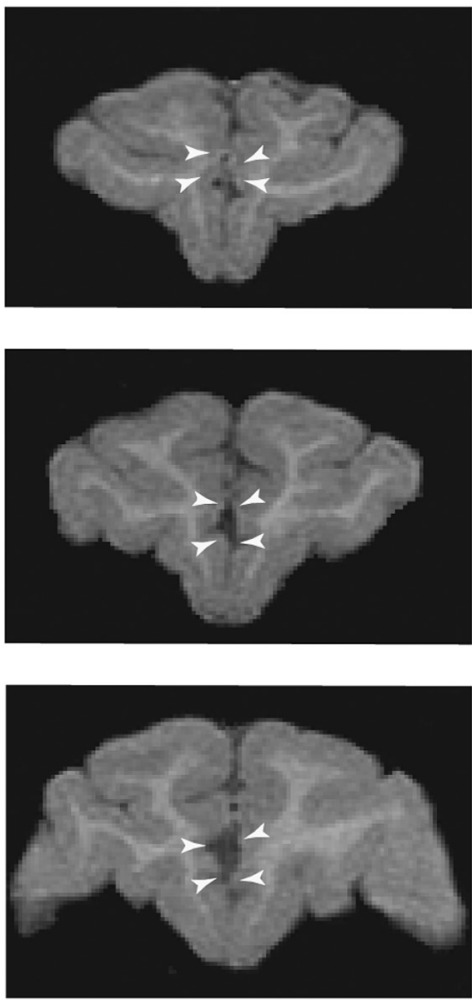

PL 2
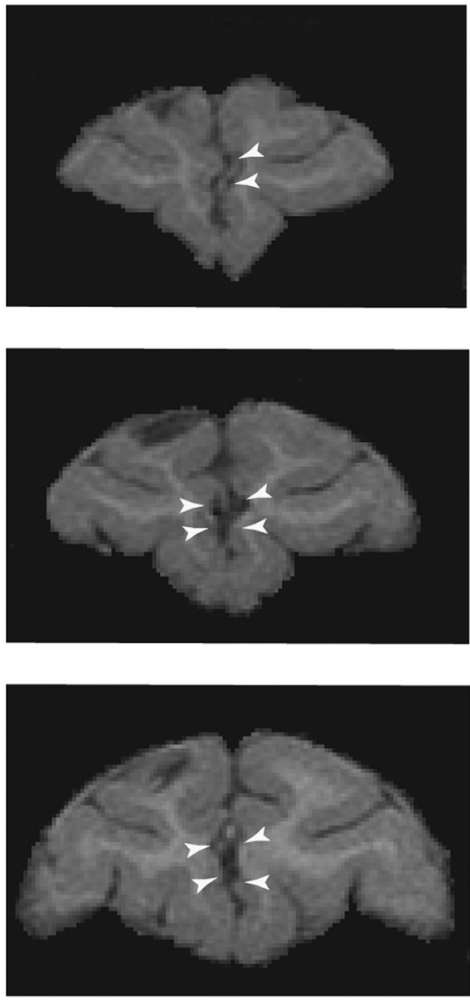

Figure 2. The left column shows coronal sections from a representative rhesus monkey brain depicting the location and extent of the intended bilateral PL lesion. The numerals indicate the distance (millimeters) of the sections from the interaural plane (0). The middle and right columns show the T1-weighted MR images from two monkeys with lesions of the prelimbic cortex (PL 1 and $\mathrm{PL}$ 2) at levels matching the sections in the left column. White arrowheads on the MR images demarcate the lesions. Compare and contrast line drawings of the intended lesion (left column) with MR sections of the cases illustrated (middle and right columns).

and pretraining for the tap/hold task. A single stimulus, a solid red square $(5 \times 5 \mathrm{~cm})$, was used for later phases of training and for the main task. The food rewards were peanuts and Skittles (Mars Foods). Rewards were dispensed from an automated dispenser (Med Associates) that was mounted on top of the testing chamber; peanuts and Skittles were delivered into a cup located to the left of the monitor. All tasks were controlled and behavioral data collected by a computer using custom software (Ryklin Software).

\section{Behavioral testing}

Our experiment required monkeys to perform two different actions (tap and hold) on a touch-sensitive screen for two different food rewards. Monkeys underwent training to build up the tap and hold responses individually. Once acquired, monkeys were given a choice between the tap and hold response options on every trial. We then evaluated each monkey's response preference after changing the value of the food reward (reinforcer devaluation testing). Reinforcer devaluation tests were performed under extinction.

\section{Touch-screen training}

Monkeys first underwent training to use the touch screen, which also served to habituate them to the test chamber and reward dispensers. Two stimuli, each one associated with a different food reward (Food 1 and Food 2), were used. The stimuli assigned to Food 1 and Food 2 were counterbalanced within groups. Each trial began with the presentation of one of the two stimuli at the center of the screen. After $30 \mathrm{~s}$ the stimulus disappeared, the associated reward was delivered, and the intertrial interval (ITI), which was variable with a mean of $10 \mathrm{~s}$, began. If the monkey spontaneously touched the stimulus before the $30 \mathrm{~s}$ had elapsed, the trial ended, the associated reward was delivered, and the ITI began. Each session comprised 50 trials, which were evenly divided between the two stimuli. The stimulus presentation followed a pseudorandom order. Monkeys were given one session per day. The criterion for moving to the next stage was 40 responses in 50 trials for a single session.

\section{Tap/hold training: phase 1}

The aim of this procedure was to train the monkeys to perform two different actions: tap (six touches to the response zone on the screen within $2 \mathrm{~s}$ ) and hold (steady contact with the response zone on the screen for $2 \mathrm{~s}$ ). Monkeys proceeded through a series of stages until they acquired these two mutually exclusive responses to the touch screen. The same two stimulus-reward pairings that were used during touch-screen training were used in this phase except that the stimuli were now smaller $(3.5 \times$ $3.5 \mathrm{~cm}$ ). Also, rather than appearing at the center of the screen, they were presented on the left and right, $6.5 \mathrm{~cm}$ from the center of the screen. The stimuli assigned to tap and hold responses were counterbalanced within groups. The tap stimulus was always presented on the left side of the screen, and the hold stimulus was always presented on the right.

Tap and hold responses were trained in separate sessions, conducted back to back, and their order was alternated on a daily basis. Monkeys were trained on progressively more complex responses in stages from a single touch (first stage) to the final tap and hold responses (final stage). The exact increments were adapted to the specific needs of individual monkeys. In general, successive tap training stages were incremented one tap at a time. At the same time, the time interval within which the tap response had to be completed was gradually reduced from 15 to $2 \mathrm{~s}$. Across subsequent hold training stages, the cumulative hold time was extended from $50 \mathrm{~ms}$ to $2 \mathrm{~s}$ in increments of $100-1000 \mathrm{~ms}$, with smaller increments earlier in training. In parallel, the time interval within which the hold response had to be made was gradually reduced from 15 to $2 \mathrm{~s}$.

Each session consisted of 50 trials. A trial began when the stimulus appeared on the screen. If the monkey completed the correct response, 


\section{Intended lesion}

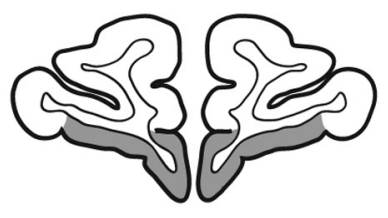

$+36$

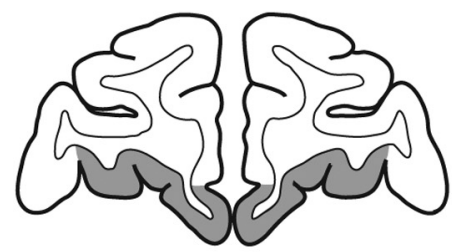

$+32$

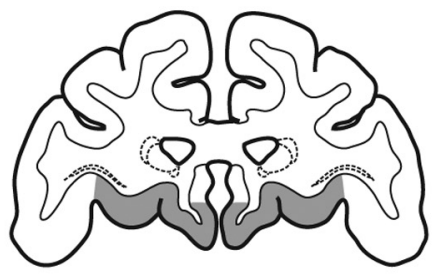

$+28$
PFo 1
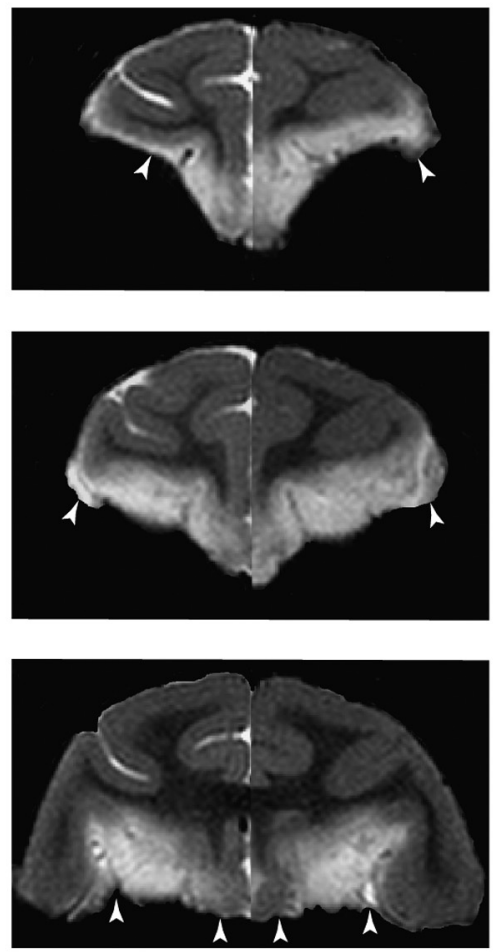

PFo 3
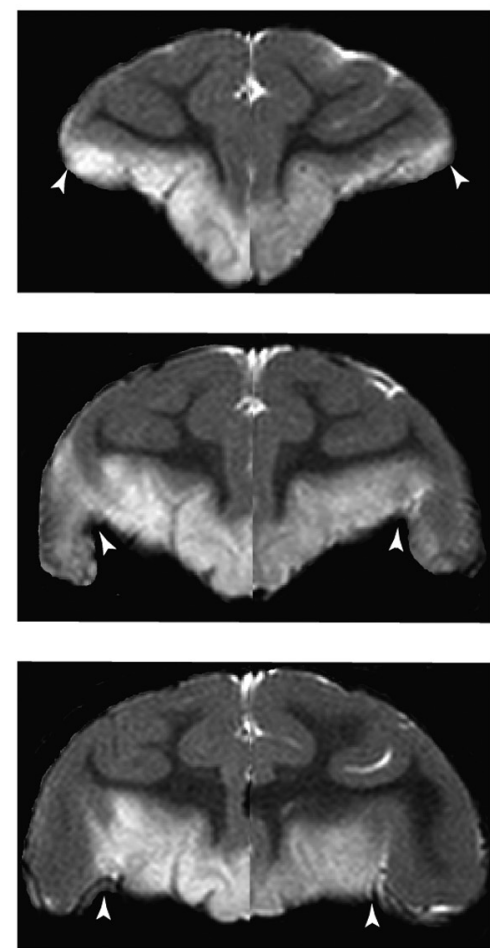

Figure 3. The left column shows coronal sections from a representative rhesus monkey brain depicting the location and extent of the intended bilateral PFo lesion. The numerals indicate the distance (millimeters) of the sections from the interaural plane (0). The middle and right columns show the T2-weighted MR images from two monkeys that received injections of excitotoxins in the PFo (PFo 1 and PFo 3) at levels matching the sections in the left column. For cases PFo 1 and PF03, the images of the left and right hemispheres are from two different MR scans; the two image halves have been joined at the midline for ease in viewing. The white areas are regions of hypersignal attributable to edema resulting from the injection of excitotoxin and are taken as a reflection of the extent of the lesion. White arrowheads on the MR images demarcate the lesions. Compare and contrast line drawings of the intended lesion (left column) with MR sections of the cases illustrated (middle and right columns).

the stimulus disappeared, the reward associated with that response was delivered, and the ITI began. If the correct response was not completed with the trial limit of $30 \mathrm{~s}$, the stimulus disappeared and the ITI began. No correction trials were given. The ITI was variable with a mean of $10 \mathrm{~s}$ (range, 5-15 s); if the monkey touched the screen during the ITI, the ITI was reset.

Monkeys were required to attain 45 correct responses in 50 trials for two successive sessions to move from the first stage to the second. After that, monkeys had to reach a criterion of 45 correct responses in 50 trials for one session to graduate to the next training stage. To complete the final stage of phase 1 tap/hold training, monkeys were required to perform 45 correct responses in 50 trials for three consecutive sessions for each session type (tap and hold). The third and final criterion session for each response was required to be on the same day.

\section{Tap/hold training: phase 2}

During this phase, monkeys were trained to make the tap and hold responses when reward was delivered on a probabilistic, random-ratio (RR) schedule. Use of the RR schedule is a standard approach intended to promote goal-directed behavior (Dickinson et al., 1983), one that encourages responding during test sessions in which there is no reward delivery (i.e., extinction).

This stage began in a similar manner to the final stage of phase 1 ; the tap and hold responses were trained in separate, back-to-back sessions, and the order of session response type alternated on a daily basis. However, unlike phase 1 , in phase 2 the tap and hold response zones were demarcated by identical red squares $(5 \times 5 \mathrm{~cm})$. In addition, across sessions, monkeys progressed from performing the tap and hold responses for continuous reinforcement (reward is delivered with a probability $p=1$ for correct responses) to an RR4 schedule, in which reward is delivered with a probability $p=0.25$. This transition was implemented in steps of $p=0.25$. If a monkey made a correct response, the stimulus disappeared, the designated reward was delivered (or not) according to an RR4 schedule, and the variable ITI of mean $10 \mathrm{~s}$ began. If no correct response was made, the trial ended after $30 \mathrm{~s}$ and the ITI began. Before moving to the next RR step, monkeys were required to perform 45 correct responses in 50 trials for a minimum of two consecutive sessions of both the tap and hold response. In addition, the final tap and hold sessions were required to fall on the same day.

\section{Tap/hold main task}

In the main task, both response options were available for choice on every trial. That is, monkeys learned to perform the tap and hold responses when both response zones were offered concurrently. The tap and hold stimuli were presented in the same position on the screen (tap on the left, hold on the right) as in previous training stages. Other than the requirement to make a choice between two responses, these sessions progressed in a similar manner to those during tap/hold training (phase 2). Each trial began with the appearance of the two red squares on the monitor screen. If a monkey made a correct response-either a tap on the left or a hold on the right - the stimuli disappeared, the designated reward was delivered (or not) based on an RR4 schedule, and the variable ITI began, as in the earlier training. If no correct response was made within the trial limit of $30 \mathrm{~s}$, the stimuli disappeared, signaling the end of the trial, and the ITI began. Monkeys received one 50-trial session per day.

The probability of reward being delivered after a correct response was reduced in steps from $p=1$ to $p=0.5$ and, finally, to $p=0.25$. The criterion to move to a reward schedule of lower probability was set at 45 correct responses in 50 trials for two consecutive sessions. After two sessions at $p=0.25$, the number of rewards delivered for a correctly 
performed action was adjusted over several sessions to equate for food preferences. This was done to balance responding between tap and hold. When the response distribution between tap and hold was deemed to be approximately equivalent and stable across sessions, monkeys were tested for their responses to reinforcer devaluation.

\section{Reinforcer devaluation test}

Monkeys underwent tests on 4 separate days to assess response preferences after devaluation of a food reward associated with one of the two responses. On each test day, monkeys were fed one food in a selective satiation procedure intended to temporarily lower the value of that food. The monkeys were then tested under extinction for tap/hold responses in the choice format. These tests were meant to ascertain whether the monkeys would alter the pattern of their responses based on the current value of the food outcome, or goal. Between test sessions, monkeys received retraining on the main task to overcome any possible reduction in baseline responding resulting from extinction testing.

Selective satiation procedure. A known weight of one of the two food rewards was placed in the food hopper $(7.7 \mathrm{~cm}$ width $\times 10.3 \mathrm{~cm}$ length $\times$ $7.7 \mathrm{~cm}$ height) attached to the front of the monkey's cage. The monkey was left to eat the food unobserved but checked by the experimenter periodically. If at any point all of the food had been eaten, the hopper was refilled. After $30 \mathrm{~min}$, the experimenter began observing the monkey through a window in the door to the monkey housing room. When the monkey refrained from taking food from the hopper for the entirety of a 5 min period, the selective satiation was deemed to be complete. The monkey was taken from its home cage to the test apparatus within $10 \mathrm{~min}$ of completing the satiation procedure. The experimenter recorded the time spent in the selective satiation procedure and the total amount of food consumed by the monkey. If food had been dropped on the cage floor, the number of pieces was counted and taken into account in calculating the total amount of food eaten.

Extinction test. After selective satiation, monkeys were tested on tap/ hold choices. The same procedures were in force as during tap/hold main task, with two exceptions. First, the test session was conducted under extinction; no rewards were delivered after either a tap or a hold response. This was done to eliminate the possibility that responding was influenced by outcome-response associations that might be activated after food delivery. Second, because we assumed that the monkeys would quickly cease responding in extinction, sessions comprised only 15 trials. The number of tap and hold responses and response omissions (failure to make either a tap or a hold response within $30 \mathrm{~s}$ ) were recorded by the computer. When either a tap or hold response was made, the latency to begin that response was recorded.

The order in which the two foods were devalued followed an A-B-B-A design; whether Food 1 or Food 2 was devalued first was counterbalanced across monkeys in each lesion group. Each extinction test was followed by 2 days rest and a minimum of 2 days retraining. This procedure was followed to ensure there were no long-lasting effects of the selective satiation procedures. When monkeys had reacquired a criterion of 45 correct responses in 50 trials for two consecutive sessions on the main task, they were given the next extinction test.

\section{Food-preference test}

Immediately after each reinforcer devaluation test, monkeys were given a food-preference test in which they were presented with Food 1 and Food 2 , one each on the experimenter's outstretched hands. The monkey was allowed to choose only one item, and a record was made of that choice. This was repeated three more times, providing a total of four trials per preference test.

\section{Results}

To summarize the behavioral procedures, rhesus monkeys with preexisting, bilateral lesions of the amygdala, PFo, or PL and unoperated control monkeys were trained to perform two different instrumental responses: tap and hold. They performed their responses on a touch-sensitive screen for two different foods, peanuts or Skittles, one associated with a tap response and the other associated with a hold response. The monkeys were then
Table 1. Mean sessions to reach criterion on each of the three training stages for the three experimental groups and controls

\begin{tabular}{llll}
\hline & Training phase 1 & Training phase 2 & Main task \\
\hline CON & 13.3 & 12.9 & 16.0 \\
AMG & 19.6 & 11.3 & 16.3 \\
PL & 14.6 & 14.6 & 15.0 \\
PFo & 17.0 & 12.8 & 16.4 \\
Mean & 15.4 & 12.3 & 15.8
\end{tabular}

Values for training phases 1 and 2 reflect the mean of tap and hold sessions. CON, Unoperated control monkeys; AMG, monkeys with bilateral excitotoxic lesions of the amygdala; PL, monkeys with bilateral aspiration lesions of the prelimbic cortex; $\mathrm{PF} 0$, monkeys with bilateral excitotoxic lesions of the orbital prefrontal cortex.

fed one of these two foods to satiety and tested under extinction for the effect of sensory-specific reinforcer devaluation. We expected that unoperated control monkeys would show a reduction in the response associated with obtaining the devalued food (i.e., a devaluation effect). If any of the brain regions under investigation-PFo, PL, and amygdala - is essential for goal-directed behavior, then monkeys in one or more of the operated groups should exhibit reduced devaluation effects.

\section{Comparison of control groups}

One control monkey (AMG-CON 2) was removed from the experiment because it exhibited difficulty in learning the tap and hold responses during phase 1 of training. Specifically, AMGCON 2 required a mean of 21 sessions to acquire the two responses, which is almost 2 SDs above the group mean (mean \pm 2 $\mathrm{SD}=21.4$ ). Thus, there were three monkeys in group AMGCON. Comparison of the two control groups (AMG-CON and $\mathrm{PL} / \mathrm{PFo}-\mathrm{CON}$ ) during phase 1 of training revealed no group difference in days to criterion for acquisition of the tap and hold responses (one-way ANOVA, $F_{(1,5)}=1.86, p>0.05$ ). Comparison of extinction test performance in the two control groups in a $2 \times 2$ mixed ANOVA with factors of group (AMG-CON, PL/ PFo-CON) and response (devalued, nondevalued) produced a main effect of response $\left(F_{(1,5)}=13.80, p<0.05\right)$ but no main effect of group or group $\times$ response interaction (maximum $\left.F_{(1,5)}=3.56, p>0.05\right)$. These findings show that both groups of controls showed robust reinforcer devaluation effects, i.e., a preference for the response associated with the nondevalued reward, but did not differ from each other in their pattern of responding. Because there was no difference in performance between the two control groups, they were combined into one control group $(\mathrm{CON})$ for the purpose of subsequent analyses.

\section{Tap/hold training}

The mean number of sessions each group of monkeys required to attain criterion at each of the three training stages is presented in Table 1. A $4 \times 3$ mixed ANOVA on the number of sessions to criterion with factors of group (CON, AMG, PL, PFo) and training stage (phase 1 , phase 2 , main task) revealed no main effect of group or interaction between group and training stage (maximum $\left.F_{(6,26)}=1.04, p>0.05\right)$, indicating that all monkeys reached criterion performance at a similar rate on each stage. However, there was a main effect of training stage $\left(F_{(2,26)}=3.53\right.$, $p<0.05)$, indicating that, on average, some stages took longer to complete than others.

\section{Selective satiation}

Monkeys ate a mean of $229.40 \mathrm{~g}$ during each of the four selective satiation sessions. A $4 \times 4$ mixed ANOVA with factors of group (CON, AMG, PL, PFo) and devaluation session (1-4) revealed no main effect of session $(F<1)$, which shows that the amount of 


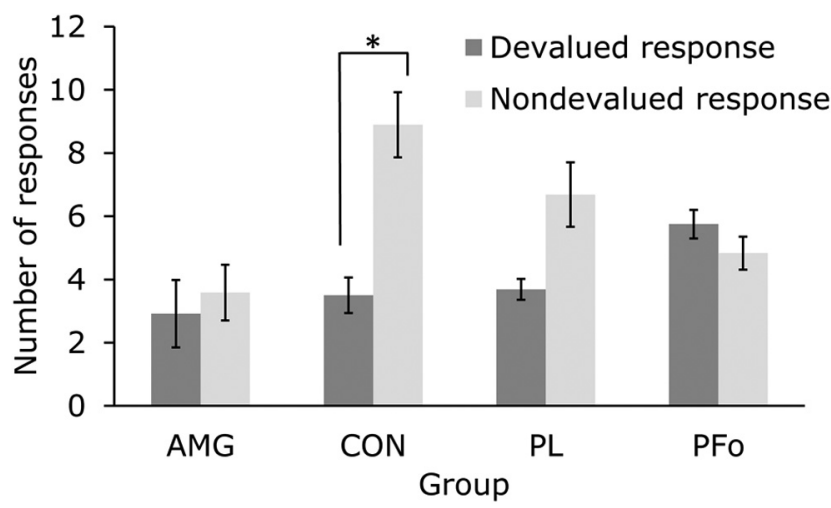

Figure 4. Mean $\pm S E M$ number of responses made during sessions conducted under extinction averaged across the $4 \mathrm{~d}$ of devaluation testing. There were 15 trials per session, and on each there were two response options available to the monkey: tap/hold response associated with the devalued reward (Devalued response), and tap/hold response associated with the nondevalued reward (Nondevalued response). CON, Unoperated control monkeys; AMG, monkeys with bilateral excitotoxic lesions of the amygdala; PL, monkeys with bilateral aspiration lesions of prelimbic cortex; PFo, monkeys with bilateral excitotoxic lesions of orbital prefrontal cortex. ${ }^{*} p<0.05$, significant difference between devalued and nondevalued responses performed during the extinction tests, as identified by a simple effects analysis.

food eaten across devaluation sessions did not differ significantly (mean food consumed: session 1, $234.38 \mathrm{~g}$; session 2, $241.76 \mathrm{~g}$; session 3, $219.79 \mathrm{~g}$; session 4, $221.65 \mathrm{~g}$ ). There was also no main effect or interaction involving group $(F$ values $<1)$, indicating that monkeys with amygdala, PL, or PFo lesions and controls did not differ in their food consumption across selective satiation sessions.

\section{Extinction test}

The extinction test, which was performed immediately after selective satiation, provided our main measure of goal-directed behavior. On each trial, monkeys chose between the action associated with the devalued food and the action associated with the nondevalued (i.e., temporarily higher-value) food. The data from the four extinction sessions were combined, and the mean responses were subjected to a $4 \times 2$ mixed ANOVA with factors of group (CON, AMG, PL, PFo) and response (devalued, nondevalued).

Results are summarized in Figure 4. The ANOVA produced a main effect of response $\left(F_{(1,13)}=8.01, p<0.05\right)$ and a group $\times$ response interaction $\left(F_{(3,13)}=4.36, p<0.05\right)$, indicating that the selective satiation procedure produced different patterns of responding across groups during the extinction test. Simple effects analyses of the interaction provided additional insight into the group differences. First, as expected, controls showed a reinforcer devaluation effect; after selective satiation, they produced a significantly greater number of responses associated with the nondevalued food contrasted with the devalued food $(p<0.05)$. However, there was no significant difference in monkeys with amygdala or PFo lesions ( $p>0.05)$, indicating that the lesion disrupted the reinforcer devaluation effect in both of these two groups. Although visual inspection of Figure 4 suggests that the PL group behaved like controls, monkeys with PL lesions also showed no significant difference in performing responses associated with the devalued and nondevalued food ( $p=0.051)$; therefore, according to this measure, the devaluation effect was disrupted in the PL group, too. There was no significant correlation between the extent of the lesion and responding (ratio of devalued responses to nondevalued responses) (Pearson's $\left.r^{2}=-0.36, p=0.65\right)$.

Both PFo and AMG groups differed from controls in the level of responding associated with the nondevalued reward $(p<$

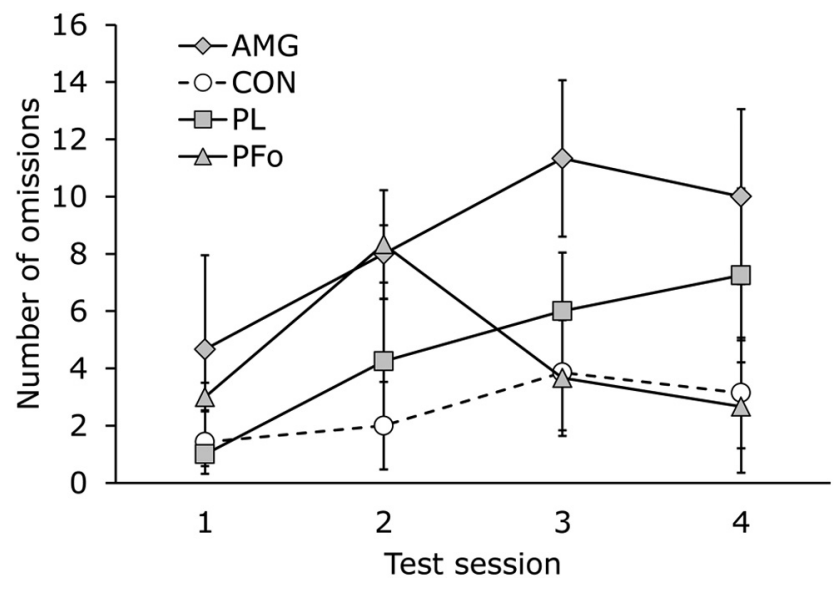

Figure 5. Mean \pm SEM number of omissions (failure to make either a tap or hold response) during sessions conducted under extinction on the $4 \mathrm{~d}$ of devaluation testing. CON, Unoperated control monkeys; AMG, monkeys with bilateral excitotoxic lesions of the amygdala; PL, monkeys with bilateral aspiration lesions of prelimbic cortex; PFo, monkeys with bilateral excitotoxic lesions of orbital prefrontal cortex.

0.05). Intact monkeys chose the action associated with the higher-value food significantly more often than those with lesions of either PFo or the amygdala. There was also a significant difference in the level of responding associated with the devalued reward between the PFo group and both controls and monkeys with amygdala lesions $(p<0.05)$. Monkeys in the PFo group chose the devalued action more often than these other two groups. The PL group did not differ from controls (or other lesion groups) when responses associated with either the devalued or nondevalued reward were considered individually. Despite the disruption of the devaluation effect (within-group difference in responding associated with the devalued and nondevalued reward) in the PL group, these monkeys did not differ from controls in their level of responding to either the devalued or nondevalued reward when they were considered separately. Accordingly, the results from the PL group are equivocal.

The ANOVA also revealed a main effect of group $\left(F_{(3,13)}=\right.$ $4.41, p<0.05)$ for the overall level of responding. Individual post hoc contrasts [Tukey's honestly significant difference (HSD) procedure] showed that overall responding of monkeys in group AMG was significantly lower (i.e., more omissions were made) relative to controls. No other comparisons were significant.

Given that the post hoc analyses indicated that the AMG group made a significantly greater number of omissions than the controls, we considered the number of omissions in more detail (Fig. 5). In a previous study using object displacement followed by extinction, monkeys with amygdala lesions showed faster extinction relative to controls (Izquierdo and Murray, 2005), a phenomenon revealed by an interaction of lesion with the number of omissions across blocks of trials. To investigate the possibility of a similar result here, we considered the number of omissions across the four test sessions. A $4 \times 4$ mixed ANOVA with factors of group (CON, AMG, PL, PFo) and test session (1-4) produced a trend toward a main effect of test $\operatorname{session}\left(F_{(3,39)}=2.46, p=0.077\right)$, reflecting the general tendency for the number of omissions to increase across subsequent extinction sessions. There was also a main effect of group $\left(F_{(3,13)}=4.41, p<\right.$ 0.05 ), and post hoc contrasts (Tukey's HSD procedure) indicated that this was attributable to a difference between AMG and CON groups in the overall number of omissions made $(p<0.5)$. Finally, there was no group $\times$ test session interaction $(F<1)$, indicating that 


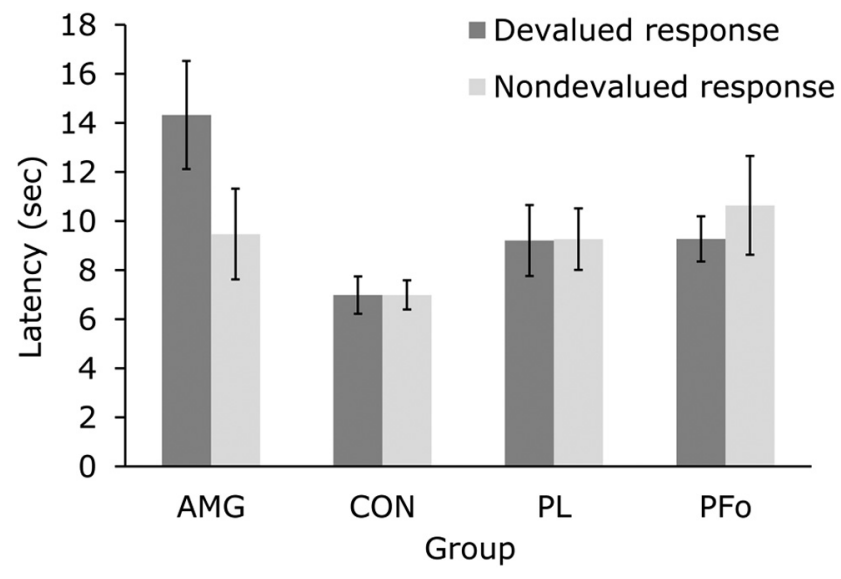

Figure 6. Mean response latency (number of seconds \pm SEM) during sessions conducted under extinction averaged across the $4 \mathrm{~d}$ of devaluation testing. There were 15 trials per session, and on each there were two response options available to the monkey: tap/hold response associated with the devalued reward (Devalued response) and tap/hold response associated with the nondevalued reward (Nondevalued response). CON, Unoperated control monkeys; AMG, monkeys with bilateral excitotoxic lesions of the amygdala; PL, monkeys with bilateral aspiration lesions of prelimbic cortex; $\mathrm{PF}$, monkeys with bilateral excitotoxic lesions of orbital prefrontal cortex.

the increase in omissions across test sessions did not differ between groups.

Response latency was also examined (Fig. 6). A $4 \times 2$ mixed ANOVA with factors of group (CON, AMG, PL, PFo) and response (devalued, nondevalued) revealed a main effect of group $\left(F_{(3,13)}=3.65, p<0.05\right)$, indicating that the overall latency to respond differed across the four groups. Post hoc contrasts (Tukey's HSD procedure) indicated that this was attributable to a longer latency to respond in the AMG group compared with controls $(F<0.005)$. No other contrast was significant. There was a group $\times$ response interaction $\left(F_{(3,13)}=3.98, p<0.05\right)$ but no main effect of response $\left(F_{(1,13)}=1.89, p>0.05\right)$, indicative of the different pattern of response latencies seen across the four groups as shown in Figure 6. Additional insight into the group differences were gleaned from simple effects analyses of the interaction. Surprisingly, AMG was the only group to show a significant difference in latency in performing the responses associated with the devalued and nondevalued food $(p<0.05)$. In addition, the latency in performing the response associated with the devalued food was significantly greater in the AMG group than in the other three groups $(p<0.05)$.

\section{Food-preference test}

Across all food-preference tests, there were only three of 272 occasions on which a monkey chose the food it had consumed to satiety before the behavioral testing session. This occurred once each in groups AMG, PL, and PFo. A one-sample two-tailed $t$ test conducted on the mean of responding on all four food-preference tests indicated that selection of the more highly valued (i.e., nonsated) food was significantly different from chance $\left(t_{(25)}=38.35 p<0.001\right)$. A one-way ANOVA conducted on the mean for all four foodpreference tests revealed no group differences $(F<1)$.

\section{Discussion}

We devised a novel task to assess the contribution of the prefrontal cortex and amygdala to goal-directed behavior in macaque monkeys. As expected, the instrumental responses of intact monkeys were guided by the current value of the reward (goal). After selective satiation, they showed a devaluation effect: a bias toward performing responses associated with a nondevalued food over those associated with a devalued food. Amygdala and PFo lesions severely disrupted the devaluation effect, effectively rendering instrumental responding insensitive to changes in the value of the goal. PL lesions produced equivocal results.

\section{Assessing goal-directed behavior}

Previous devaluation studies in monkeys have revealed a role for the amygdala and PFo in the guidance of behavior by the current value of reward (Málková et al., 1997; Baxter et al., 2000; Izquierdo et al., 2004; Wellman et al., 2005; Izquierdo and Murray, 2007; Machado and Bachevalier, 2007; Rudebeck and Murray, 2011a; West et al., 2011). The present findings advance this work in two ways.

First, the previous studies involved reaching for and displacing objects. Because this kind of behavior might be supported by pavlovian approach (stimulus-outcome) or instrumental (response-outcome) mechanisms, the previous reports do not demonstrate unequivocally that the lesions disrupted goaldirected behavior. The current study does so; the amygdala and PFo play a necessary role in linking actions with the current value of the goal or using that knowledge to guide behavior. The contrived nature of the tap and hold responses makes it unlikely that they reflect innate responses under purely pavlovian control (e.g., conditioned approach).

Second, the previous studies in monkeys used reinforcers in the test phase. Reinforcers could support the formation of updated stimulus-response associations to guide choices and may also cue responding via (backward) outcome-response associations. In the present experiment, responses were made under extinction conditions and so avoided these interpretational issues.

The deficit caused by PFo and amygdala lesions in this study is specific to goal-directed responding. It cannot be attributed to a motor deficit; the monkeys' responses were clearly differentiated and performed in a stereotyped manner. Because all monkeys were trained to criterion before moving to the test phase, the difference in responding seen during the test cannot be attributable to group differences in baseline responding. In addition, because one action was performed on the left and the other on the right side of the touch screen, we also considered whether a deficit in spatial processing might account for the impairments we observed. This possibility seems unlikely; neither amygdala nor PFo lesions disrupt spatial processing in monkeys (Butter, 1969; Murray and Wise, 1996; Meunier et al., 1997). Furthermore, we can rule out impairments in visual perception, learning, and general motivation, because there were no group differences in the rate of acquisition during any stage of training. Their equivalent performance on the food-preference tests indicates that all groups were able to discriminate between the two foods. Finally, the present findings cannot be explained by deficiencies in satiety mechanisms, in general, or a failure for satiety to transfer from the home cage to the test room; all groups showed equivalent pretest food consumption and postsatiety food preferences.

\section{Amygdala}

Previous work in rats has shown that lesions of the amygdala disrupt devaluation effects in a range of tasks, including those drawing on instrumental mechanisms and those drawing on pavlovian mechanisms (Hatfield et al., 1996; Balleine et al., 2003; Blundell et al., 2003; Corbit and Balleine, 2005; Johnson et al., 2009). Together, the pattern of results from monkeys with amygdala lesions and controls provides validation of the devaluation procedure used in this experiment.

Although both amygdala and PFo lesions impaired the devaluation effect, we observed two differences between these groups. 
Monkeys with amygdala lesions made significantly more omissions than controls and also displayed longer latencies when performing the response associated with the devalued food, effectively hesitating before making an "incorrect" response. Monkeys with PFo lesions showed neither effect. The former effect could reflect facilitated extinction learning, as observed previously after amygdala lesions (Izquierdo and Murray, 2005). The latter effect, more intriguingly, suggests that monkeys with amygdala lesions, although not showing a devaluation effect, were on some level able to discriminate between the devalued and nondevalued reward (or the responses associated with them).

\section{PL}

Because our PL lesions only extended to $55-83 \%$ of the region as defined here, some preservation of PL function may account for the equivocal results for this group. However, against this idea, there was no relationship between the PL lesion volume and responding in the extinction test.

No published studies in monkeys have involved selective lesions of PL, but Hadland et al. (2003) found that large medial frontal lesions that included PL disrupted the ability of monkeys to select actions instructed by presentation of different food rewards associated with those actions. However, their task did not provide the direct test of goal-directed behavior that the present study did. Whether the size of the lesion or the details of experimental design might account for our equivocal result remains to be determined in future studies.

In contrast to the paucity of research on PL in monkeys, many studies performed in rats demonstrate a role for PL in goaldirected behavior in experiments similar to the present one (Balleine and Dickinson, 1998; Corbit and Balleine, 2003; Killcross and Coutureau, 2003; Ostlund and Balleine, 2005). In addition, performance on instrumental contingency degradation and outcome-cued tasks is disrupted in rats with PL lesions, which supports the idea that PL is involved in response-outcome associations and therefore goal-directed behavior (Balleine and Dickinson, 1998; Corbit and Balleine, 2003; Dwyer et al., 2010). Recent work in rats indicates that PL is specifically needed for acquisition of response-outcome associations, but once these associations have been formed, PL becomes redundant (Ostlund and Balleine, 2005; Tran-Tu-Yen et al., 2009). Similar studies in monkeys could be of value.

\section{PFo}

As indicated in the Introduction, devaluation studies in rats have identified a role in goal-directed behavior for PL, a medial prefrontal area, but not for orbitofrontal cortex. Thus, our findings of an impairment after PFo lesions appear to conflict with the rodent data. There are several possible reasons for this disparity.

First, the rodent data involve lesions of an orbitofrontal area that is not homologous with the part of the PFo studied here (Wise, 2008). So perhaps the present impairment reflects additional functions of PFo in monkeys compared with rats. Second, work in rodents might have missed some of the goal-directed (response-outcome) functions of orbitofrontal cortex attributable to specific aspects of experimental design. However, we note that the design of the current study is very similar to that used by Ostlund and Balleine (2007a). Third, the idea that PFo is involved in guiding behavior based on the value of an outcome is more complex than sometimes acknowledged. Based on findings in rats, monkeys, and humans, there is considerable support for the idea that PFo houses representations of outcomes and that those representations may enter into associations with stimuli and re- sponses; notably, such representations can be activated by events that predict the outcome before the delivery of the outcome itself, giving rise to "reward expectancy" signals (for review, see Holland and Gallagher, 2004). Although we have described our findings in terms of outcome "value," several investigators have suggested that PFo is important not for representing value per se but for representing the sensory-specific features of an outcome through which value can be accessed (Balleine et al., 2011; Schoenbaum et al., 2011). This view has garnered empirical support from studies directly assessing this type of association in rodents (Burke et al., 2008; McDannald et al., 2011). If true, then in the current task, PFo might bias instrumental response selection by enabling stimuli on the screen to influence instrumental responding by eliciting the sensory-specific aspects of the two potentially available foods (Ostlund and Balleine, 2007b).

PFo has functionally distinct subregions (Noonan et al., 2011; Rudebeck and Murray, 2011a,b; Walton et al., 2011), with medial $\mathrm{PFo}$ involved in choices between stimuli based on value and lateral PFo involved in learning, representing and updating stimulus-outcome associations (Rudebeck and Murray, 2011a,b). Both could contribute to the current task. Given the human imaging literature indicating a role for medial PFo in goal-directed behavior (Valentin et al., 2007; Gläscher et al., 2009; O'Doherty, 2011), future studies in monkeys should examine the independent contributions of the functional subdivisions of PFo to goaldirected behavior.

\section{Medial versus orbital PF}

Within prefrontal cortex as a whole, one framework emerging from studies of value-based decision making is that orbital and medial prefrontal regions are dedicated to object- and actionbased processes, respectively (Rudebeck et al., 2008; Camille et al., 2011; Rushworth et al., 2011). Our findings regarding PFo challenge that notion, at least in its simplest form. For the present task, PFo plays a necessary role in making choices between actions based on the current value of an outcome, much like it does for choices between objects.

\section{References}

Adams CD, Dickinson A (1981) Actions and habits: variations in associative representations during instrumental learning. In: Information processing in animals: memory mechanisms (Spear NE, Miller RR, eds), pp 143-165. Hillsdale, NJ: Erlbaum.

Balleine BW, Dickinson A (1998) Goal directed instrumental action: contingency and incentive learning and their cortical substrates. Neuropharmacology 37:407-419. CrossRef Medline

Balleine BW, Killcross AS, Dickinson A (2003) The effect of lesions of the basolateral amygdala on instrumental conditioning. J Neurosci 23:666675. Medline

Balleine BW, Leung BK, Ostlund SB (2011) The orbitofrontal cortex, predicted value, and choice. Ann NY Acad of Sci 1239:43-50. CrossRef Medline

Baxter MG, Parker A, Lindner CC, Izquierdo AD, Murray EA (2000) Control of response selection by reinforcer value depends on interaction of amygdala and orbital prefrontal cortex. J Neurosci 20:4311-4319. Medline

Blundell P, Hall G, Killcross S (2003) Preserved sensitivity to outcome value after lesions of the basolateral amygdala. J Neurosci 23:7702-7709. Medline

Burke KA, Franz TM, Miller DN, Schoenbaum G (2008) The role of the orbitofrontal cortex in the pursuit of happiness and more specific rewards. Nature 454:340-344. CrossRef Medline

Butter CM (1969) Perseveration in extinction and in discrimination reversal tasks following selective frontal ablations in Macaca mulatta. Physiol Behav 4:163-171. CrossRef

Camille N, Tsuchida A, Fellows LK (2011) Double dissociation of stimulus- 
value and action-value learning in humans with orbitofrontal or anterior cingulate cortex damage. J Neurosci 31:15048-15052. CrossRef Medline

Carmichael ST, Price JL (1994) Architectonic subdivision of the orbital and medial prefrontal cortex in the macaque monkey. J Comp Neurol 346: 366-402. CrossRef Medline

Carmichael ST, Price JL (1995) Limbic connections of the orbital and medial prefrontal cortex in macaque monkeys. J Comp Neurol 363:615-641. CrossRef Medline

Chudasama Y, Daniels TE, Gorrin DP, Rhodes SEV, Rudebeck PH, Murray EA (2012) Anterior cingulate cortex lesions in rhesus monkeys disrupt decision making in the object domain. Cereb Cortex. Advance online publication. Retrieved January 13, 2013. doi:10.1093/cercor/bhs266. CrossRef Medline

Corbit LH, Balleine BW (2003) The role of the prelimbic cortex in instrumental conditioning. Behav Brain Res 146:145-157. CrossRef Medline

Corbit LH, Balleine BW (2005) Double dissociation of basolateral and central amygdala lesions on the general and outcome-specific forms of Pavlovian-instrumental transfer. J Neurosci 25:962-970. CrossRef Medline

Dickinson A, Balleine B (1994) Motivational control of goal-directed action. Anim Learn Behav 22:1-18. CrossRef

Dickinson A, Nicholas DJ, Adams CD (1983) The effect of the instrumental training contingency on susceptibility to reinforcer devaluation. Q J Exp Psychol 35:35-51.

Dwyer DM, Dunn MJ, Rhodes SEV, Killcross AS (2010) Prelimbic prefrontal cortex lesions impair performance on a biconditional discrimination by disrupting goal directed responding. Q J Exp Psychol 63:417-424. CrossRef

Everitt BJ, Robbins TW (2005) Neural systems of reinforcement for drug addiction: from actions to habits to compulsion. Nat Neurosci 8:14811489. CrossRef Medline

Gillan CM, Papmeyer M, Morein-Zamir S, Sahakian BJ, Fineberg NA, Robbins TW, de Wit S (2011) Disruption in the balance between goaldirected behavior and habit learning in obsessive-compulsive disorder. Am J Psychiatry 168:718-726. CrossRef Medline

Gläscher J, Hampton AN, O'Doherty JP (2009) Determining a role for ventromedial prefrontal cortex in encoding action-based value signals during reward-related decision making. Cereb Cortex 19:483-495. CrossRef Medline

Hadland KA, Rushworth MF, Gaffan D, Passingham RE (2003) The anterior cingulate and reward-guided selection of actions. J Neurophysiol 89:1161-1164. CrossRef Medline

Hatfield T, Han JS, Conley M, Gallagher M, Holland P (1996) Neurotoxic lesions of basolateral, but not central amygdala interfere with Pavlovian second-order conditioning and reinforcer devaluation effects. J Neurosci 16:5256-5265. Medline

Holland PC, Gallagher M (2004) Amygdala-frontal interactions and reward expectancy. Curr Opin Neurobiol 14:148-155. CrossRef Medline

Izquierdo A, Murray EA (2004) Combined unilateral lesions of the amygdala and orbital prefrontal cortex impair affective processing in rhesus monkeys. J Neurophysiol 91:2023-2039. CrossRef Medline

Izquierdo A, Murray EA (2005) Opposing effects of amygdala and orbital prefrontal cortex lesions on the extinction of instrumental responding in macaque monkeys. Eur J Neurosci 22:2341-2346. CrossRef Medline

Izquierdo A, Murray EA (2007) Selective bilateral amygdala lesions in rhesus monkeys fail to disrupt object reversal learning. J Neurosci 27:10541062. CrossRef Medline

Izquierdo A, Suda RK, Murray EA (2004) Bilateral orbital prefrontal cortex lesions in rhesus monkeys disrupt choices guided by both reward value and reward contingency. J Neurosci 24:7540-7548. CrossRef Medline

Izquierdo A, Suda RK, Murray EA (2005) Comparison of the effects of bilateral orbital prefrontal cortex lesions and amygdala lesions on emotional responses in rhesus monkeys. J Neurosci 25:8534-8542. CrossRef Medline

Johnson AW, Gallagher M, Holland PC (2009) The basolateral amygdala is critical to the expression of Pavlovian and instrumental outcome-specific reinforcer devaluation effects. J Neurosci 29:696-704. CrossRef Medline

Kennerley SW, Walton ME, Behrens TE, Buckley MJ, Rushworth MF (2006) Optimal decision making and the anterior cingulate cortex. Nat Neurosci 9:940-947. CrossRef Medline

Killcross S, Coutureau E (2003) Coordination of actions and habits in the medial prefrontal cortex of rats. Cereb Cortex 13:400-408. CrossRef Medline

Levy R, Dubois B (2006) Apathy and the functional anatomy of the prefrontal cortex-basal ganglia circuits. Cereb Cortex 16:916-928. CrossRef Medline

Machado CJ, Bachevalier J (2007) The effects of selective amygdala, orbital frontal cortex or hippocampal formation lesions on reward assessment in nonhuman primates. Eur J Neurosci 25:2885-2904. CrossRef Medline

Málková L, Gaffan D, Murray EA (1997) Excitotoxic lesions of the amygdala fail to produce impairment in visual learning for auditory secondary reinforcement but interfere with reinforcer devaluation effects in rhesus monkeys. J Neurosci 17:6011-6020. Medline

McDannald MA, Lucantonio F, Burke KA, Niv Y, Schoenbaum G (2011) Ventral striatum and orbitofrontal cortex are both required for model-based, but not model-free, reinforcement learning. J Neurosci 31:2700-2705. CrossRef Medline

Meunier M, Bachevalier J, Mishkin M (1997) Effects of orbital frontal and anterior cingulate lesions on object and spatial memory in rhesus monkeys. Neuropsychologia 35:999-1015. CrossRef Medline

Murray EA, Wise SP (1996) Role of the hippocampus plus subjacent cortex but not amygdala in visuomotor conditional learning in rhesus monkeys. Behav Neurosci 110:1261-1270. CrossRef Medline

Noonan MP, Mars RB, Rushworth MF (2011) Distinct roles of three frontal cortical areas in reward-guided behavior. J Neurosci 31:14399-14412. CrossRef Medline

O'Doherty JP (2011) Contributions of the ventromedial prefrontal cortex to goal-directed action selection. Ann NY Acad Sci 1239:118-129. CrossRef Medline

Ongür D, Price JL (2000) The organisation of networks within the orbital and medial prefrontal cortex of rats, monkeys and humans. Cereb Cortex 10:206-219. CrossRef Medline

Ostlund SB, Balleine BW (2005) Lesions of medial prefrontal cortex disrupt the acquisition but not the expression of goal-directed learning. J Neurosci 25:7763-7770. CrossRef Medline

Ostlund SB, Balleine BW (2007a) Orbitofrontal cortex mediates outcome encoding in Pavlovian but not instrumental conditioning. J Neurosci 27:4819-4825. CrossRef Medline

Ostlund SB, Balleine BW (2007b) The contribution of orbitofrontal cortex to action selection. Ann NY Acad Sci 1121:174-192. CrossRef Medline

Ostlund SB, Balleine BW (2008) Differential involvement of the basolateral amygdala and mediodorsal thalamus in instrumental action selection. J Neurosci 28:4398-4405. CrossRef Medline

Rudebeck PH, Murray EA (2011a) Dissociable effects of subtotal lesions within the macaque orbital prefrontal cortex on reward-guided behavior. J Neurosci 31:10569-10578. CrossRef Medline

Rudebeck PH, Murray EA (2011b) Balkanizing the primate orbitofrontal cortex: distinct subregions for comparing and contrasting values. Ann NY Acad Sci 1239:1-13. CrossRef Medline

Rudebeck PH, Behrens TE, Kennerley SW, Baxter MG, Buckley MJ, Walton ME, Rushworth MF (2008) Frontal cortex subregions play distinct roles in choices between actions and stimuli. J Neurosci 28:13775-13785. CrossRef Medline

Rushworth MF, Noonan MP, Boorman ED, Walton ME, Behrens TE (2011) Frontal cortex and reward-guided learning and decision-making. Neuron 70:1054-1069. CrossRef Medline

Schoenbaum G, Takahashi Y, Liu TL, McDannald MA (2011) Does the orbitofrontal cortex signal value? Ann NY Acad Sci 1239:87-99. CrossRef Medline

Tran-Tu-Yen DA, Marchand AR, Pape JR, Di Scala G, Coutureau E (2009) Transient role of the rat prelimbic cortex in goal-directed behaviour. Eur J Neurosci 30:464-471. CrossRef Medline

Valentin VV, Dickinson A, O'Doherty JP (2007) Determining the neural substrates of goal-directed learning in the human brain. J Neurosci 27: 4019-4026. CrossRef Medline

Walker AE (1940) A cytoarchitectural study of the prefrontal area of the macaque monkey. J Comp Neurol 73:59-86. CrossRef

Walton ME, Behrens TE, Noonan MP, Rushworth MF (2011) Giving credit where credit is due: orbitofrontal cortex and valuation in an uncertain world. Ann NY Acad Sci 1239:14-24. CrossRef Medline

Wellman LL, Gale K, Malkova L (2005) GABA-mediated inhibition of basolateral amygdala blocks reward devaluation in macaques. J Neurosci 25:4577-4586. CrossRef Medline 
West EA, DesJardin JT, Gale K, Malkova L (2011) Transient inactivation of orbitofrontal cortex blocks reinforcer devaluation in macaques. J Neurosci 31:15128-15135. CrossRef Medline
Wise SP (2008) Forward frontal fields: phylogeny and fundamental function. Trends Neurosci 31:599-608. CrossRef Medline 